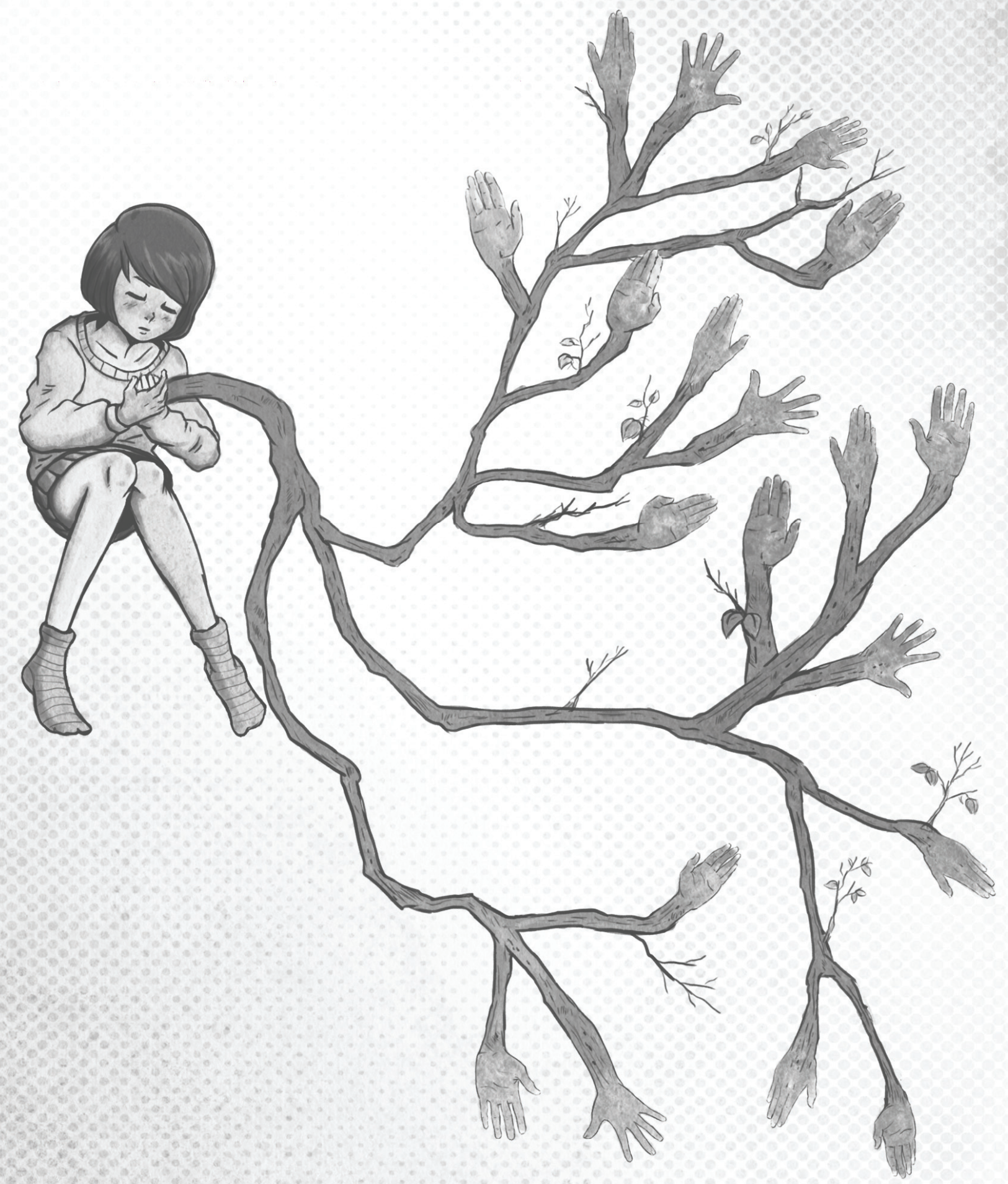

\title{
Ensayo: El Significado de la Democracia
}




\section{ENSAYO}

\section{EL SIGNIFICADO DE LA DEMOCRACIA}

The meaning of democracy

\section{Carlos Fernández Fontenoy (Perú)}

Universidad Nacional Mayor de San Marcos

cfernandez2956@yahoo.es

Doctor en Ciencias Políticas y Sociología por la Universidad

Complutense de Madrid. Profesor de la Universidad Nacional

Mayor de San Marcos

\section{Resumen}

El texto presenta una reflexión sobre la democracia con alcances de mirada hacia América Latina y el siglo XX y XXI. Buscando indicios en la historia greco-latina el artículo cree encontrar explicación al significado mismo de la palabra Democracia, más aun en consonancia con la forma de gobierno que ella trae implícita. En el panorama de latinoamerica y durante los siglos XX y el actual XXI se pueden notar diversas referencias que aportan a la reflexión, entre ellas se destaca el hecho de que muchos ciudadanos no saben siquiera hoy aun interpretar el significado de la expresión democracia.

También hay un análisis de los procedimientos y mecanismos relacionados con la representación aunque sin olvidar el reiterado tema de las mentalidades. Luego para ir concluyendo se remite en especifico al caso del Perú donde hace mención al voto de los analfabetos -excluidos secularmente del sistema político peruano- como símbolo del avance de las formas participativas democráticas en nuestra región.

\section{Resumo}

O texto apresenta uma reflexão sobre a democracia com vãos perspectiva sobre a América Latina e do século XX e XXI. Buscando pistas no história greco-romana acredita encontrar explicação muito significado da palavra democracia, ainda mais em sintonia com a forma como ela traz implícita do governo. No panorama da América Latina e em todo o hoje vigésimo e vigésimo primeiro pode notar várias referências que contribuam para a reflexão, entre eles está o fato de que muitas pessoas não sabem até hoje ainda interpretar o significado da democracia.

Há também uma análise dos procedimentos e mecanismos relacionados com a representação recordando o tema repetido de mentalidades. Então, para ir concluindo específico refere-se ao caso no Peru, onde menciona o voto-excluídos do sistema peruano analfabeto político durante séculos como um símbolo do progresso da democráticas formas participativas em nossa região.

\section{Palabras Clave:}

Democracia, historia, america latina, Peru,

democracia moderna

\section{Palavras Chave:}

democracia, história, América, Peru, democracia moderna,

\begin{abstract}
This paper presents a reflection on democracy and reaches its perspective on Latin America and the $X X$ and $X X I$ century. Searching for evidence in Greco-Roman history, the article finds the meaning of the word democracy, even more in line with the way of government implicit in it. In the panorama of Latin America and throughout the twentieth and twenty-first centuries several references can be noted that contribute to the reflection, among them, stands out the fact that many citizens don't even know today to interpret the meaning of democracy.

There is also an analysis of the procedures and mechanisms relating to the representation while recalling the repeated theme of mentalities. To conclude, the article refers specifically to the case of Peru and brings out the topic of the illiterate voting, secularly excluded from the Peruvian political system, as a symbol of the progress of democratic participatory forms in our region.
\end{abstract}




\section{SU SIGNIFICADO}

\section{La democracia en la historia}

Cuando se estudia el complejo tema de la democracia, es posible diferenciar en términos históricos y de contenido la llamada democracia antigua de la democracia moderna. Cuando se habla de la democracia antigua, se hace referencia a la democracia que surgió en Grecia hace cerca de 2,500 años. Sin embargo este ensayo no gira entorno a este tipo de democracia precursora o auroral, pero excluyente de un sector importante de la población de las polis, como sucedió en el caso de la Atenas de aquella época. Hay autores que encuentran interesantes prácticas democráticas en la antigua República Romana, pero éste tampoco es el objeto principal de este estudio.

El interés de éste artículo es el de reflexionar sobre la concepción y las formas que viene adquiriendo la democracia moderna en la América Latina, especialmente durante los siglos XX y XXI.

Nuestra especie humana, la del homo sapiens u homo moderno, existe desde hace aproximadamente 160.000 años. La democracia antigua, como mencionamos, aparece dentro de este horizonte histórico, luego de alrededor de 158.500 años, y duró menos de 200 años en la Grecia de los grandes filósofos clásicos.

En el caso de la democracia moderna, si se toma como referente histórico, de su inicio, la implementación del sufragio universal (fines del siglo XIX, comienzos del XX), este sistema político no tiene de existencia permanente más de 135 años, en el caso europeo, y menos aún en América Latina. En términos mundiales, ¿qué sistemas políticos o formas de gobierno existieron antes de estos últimos 135 años, es decir, en los 159.865 años anteriores, aproximadamente?

En este largo período pre-democrático primaron sistemas políticos autoritarios, totalitarios, despóticos, etc., es decir, formas de gobierno no democráticas, en las cuales los seres humanos (hombres y mujeres) no eran considerados ni libres ni iguales y la mayoría fueron excluidos del sistema político de sus respectivas sociedades.

Desde esta perspectiva histórica, se puede constatar que la democracia moderna es una concepción filosófica y una práctica política de muy reciente data. Si se analiza nuestra historia humana en períodos de larga duración, es posible afirmar que la democracia, de los modernos, recién está en sus etapas iniciales, haciendo su primer aprendizaje, con todo lo que ello significa a nivel de experimentación y de errores cometidos. 


\section{SUS PRINCIPIOS}

\section{Lo novedoso la democracia}

Los seres humanos, a través de casi toda la historia (pre-democrática) no han aceptado o pensado que todas las personas poseen el derecho a ser libres, y menos aún, que todos sean iguales entre sí.

Una constante de la historia de América Latina, ha sido la perdurable creencia que unas razas o culturas son superiores a otras, y que los seres humanos no son iguales. Hay personas que pueden creer que los japoneses son superiores a los coreanos, o que la raza asiática es superior a la negra, los alemanes a los polacos, que los hombres son superiores a las mujeres, o que los heterosexuales los son a los homosexuales.

Es obvio que existen diferencias entre las distintas culturas y razas, y que entre ellas han desarrollado diversos aspectos de manera desigual y en diversos momentos históricos. En muchos aspectos, la cultura oriental antes del siglo XIII fue "superior" a la cultura occidental, como lo demuestran los grandes logros de la cultura china, hindú o la del mundo árabe. Estas culturas, de variadas maneras, influenciaron y fueron la base del posterior desarrollo europeo. Por ejemplo, no es posible comprender el surgimiento del renacimiento y del humanismo sin el aporte crucial de la cultura árabe'. En la actualidad, pareciera que se estuviera dando un proceso a la inversa: que el mundo o la cultura oriental está creciendo económica y militarmente, gracias a la apropiación que vienen realizando a través de una serie de "productos culturales" occidentales, como lo son: la ciencia y la tecnología. El auge precursor de Japón, seguido del sudeste asiático, la India o China, son un ejemplo de lo que se afirma. Lo novedoso de la democracia moderna, consiste en considerar que todos los hombres y mujeres de la especie humana son iguales y libres desde que se nace. Aceptar esta idea, trae como consecuencia inevitable un drástico cambio en las relaciones de los seres humanos entre sí. Una cosa es relacionarse con un semejante al que se le considera inferior, y, otra, con uno que se considera como "un igual".

Por ejemplo, hace menos de 100 años en Estados Unidos de América los habitantes de raza negra eran tratados como seres inferiores a los pobladores de raza blanca, y por esta razón, por ejemplo, no podían compartir los mismos espacios públicos con ellos. Esta mentalidad racista, si bien perdura todavía en amplios sectores de la población blanca norteamericana, ha disminuido considerablemente en los últimos 50 años, permitiendo que un ciudadano de origen afroamericano como Barack Obama hubiera llegado a la presidencia en ese importante país.

En Latinoamérica el asunto no es muy diferente. Si se habla de desigualdades de género, por ejemplo, en Perú hace menos de 60 años que se concedió el derecho al sufragio a las mujeres, y todavía está muy lejos el día que se pueda hablar de una sociedad donde las mujeres sean tratadas igual que los varones.

1. Los árabes, por ejemplo, desarrollaron el álgebra, la astrología, la alquimia, introdujeron en Europa la pólvora proveniente de China, trasmitieron el número "cero" proveniente de la India, aportaron nuevas formas arquitectónicas o la traducción y comentarios de los clásicos Griegos al latín para que pudiera "renacer" la cultura helénica en Europa. 
La aceptación por la igualdad de derechos entre los seres humanos de diferentes culturas, razas, sexos, creencias, etc. está provocando un cambio radical en las relaciones interpersonales a nivel planetario. Este es un proceso lento pero que está cambiando todo un patrón de comportamiento cultural de siglos de existencia en la historia humana ${ }^{2}$. Desde esta perspectiva, estamos recién en se puede afirmar que la sociedad está ad portas de los inicios de una nueva civilización, la democrática ${ }^{3}$, que poco apoco está transformando las interrelaciones asimétricas pre-democráticas, por otras basadas en la convicción de que todos los seres humanos son libres e iguales.

\section{El contenido y los procedimientos de la democracia}

Hasta ahora se ha explicado el significado de la democracia, de su contenido, de sus principios y pilares fundamentales (la libertad e igualdad), es decir, de lo que algunos autores denominan la democracia sustantiva ${ }^{4}$. Pero la democracia es algo más, también está conformada por una serie de derechos y procedimientos - principalmente electorales - a través de los cuales todos los ciudadanos eligen a sus gobernantes.

En efecto, uno de los legados de la democracia griega, y en particular la ateniense, fue la que enseñó la existencia de otras formas de gobierno y la de seleccionar a los gobernantes. Pero esa democracia de los antiguos no consideraba a todos los seres iguales y, por lo tanto, con derechos ciudadanos porque excluyó de su sistema político a las mujeres (alrededor del 50\% de la población), a los extranjeros, por períodos, a los que no eran hijos de padres y madres atenienses y a los esclavos, es decir, a la gran mayoría de los habitantes de la polis ateniense.

Esta democracia antigua, por lo tanto, era mucho más elitista, exclusiva y excluyente que la democracia actual. Sin embargo, es importante recordar, que en los inicios de la democracia moderna -con sufragio universal- , sectores importantes de la población como las mujeres y personas -generalmente de razas no blancas- fueron inicialmente excluidos del sistema político, porque no podían sufragar ni ser candidatos a ningún cargo público5. Felizmente, con el andar del siglo XX, estos sectores fueron paulatinamente incluidos, y adquirieron el derecho a elegir y ser elegidos, es decir, considerados como ciudadanos con plenos derechos y deberes.

Pero para luchar por el derecho a la igualdad política -derecho al sufragio en este caso-, primero, los individuos adquirieron la conciencia de "ser iguales" a los otros; luego, se presentaron las luchas sociales para lograr la constitucionalización de este derecho. 
Así pues, para que exista un sistema democrático en una sociedad determinada, no basta con la existencia de procedimientos electorales para la elección de sus autoridades; también sus habitantes deben tener el derecho a "participar", estar realmente incluidos en dichos procesos electorales, tanto en su calidad de candidatos como de electores ${ }^{6}$.

Desde esta perspectiva, el derecho de los individuos a elegir a sus gobernantes, es un "derecho" conquistado a través de los siglos, a partir de la conciencia de la igualdad entre todos los seres humanos. Elegir a sus representantes políticos a través de procedimientos electorales correctos es un elemento básico en toda democracia moderna, pero no basta para la existencia de la democracia. La base de toda democracia, su sustrato final, es la existencia de una población con una conciencia y una cultura política democrática. No es posible la existencia de una democracia relativamente consolidada sin la presencia de una población con una mentalidad y una cultura política democrática.

\section{La democracia en el Perú}

Es indudable que en Latinoamérica, la conciencia democrática ha ido aumentando sin detenerse en los últimos lustros.

En el caso del Perú, el apoyo al sistema democrático en el 2009 fue del 52\%, y en el 2010 dicha cifra aumentó hasta el $61 \%$, según los resultados publicados por el Latinobarómetro. El caso más relevante ha sido el de Ecuador que, en este mismo período, pasó de un apoyo a la democracia del 43\% en el 2009, al 64\% en el 2010. Por su parte Venezuela mantuvo un $84 \%$.

Existen una serie de maneras indagar o explorar las posibles causas de esta falta de simpatía hacia la democracia o de un posible desinterés, o una actitud del electorado quien al no votar implícitamente está queriendo decir: "me da igual" un gobierno autoritario a uno democrático.

En el caso del Perú, se ha encontrado una sugerente información del $\mathrm{CAD}^{7}$ referida al año 2009, en la cual se establece que el 50\% de la población del Perú no sabe ¿qué es la democracia?

\footnotetext{
$6 \quad$ Por ejemplo en Perú, solo a partir de 1979 los analfabetos conquistaron el derecho al voto.

7 Boletín CAD №83 del 28 de diciembre del 2009, Lima, Perú. Esta información fue organizada a partir de cifras oficiales del Instituto Nacional de Estadística e Informática del Perú de julio del 2009.
} 


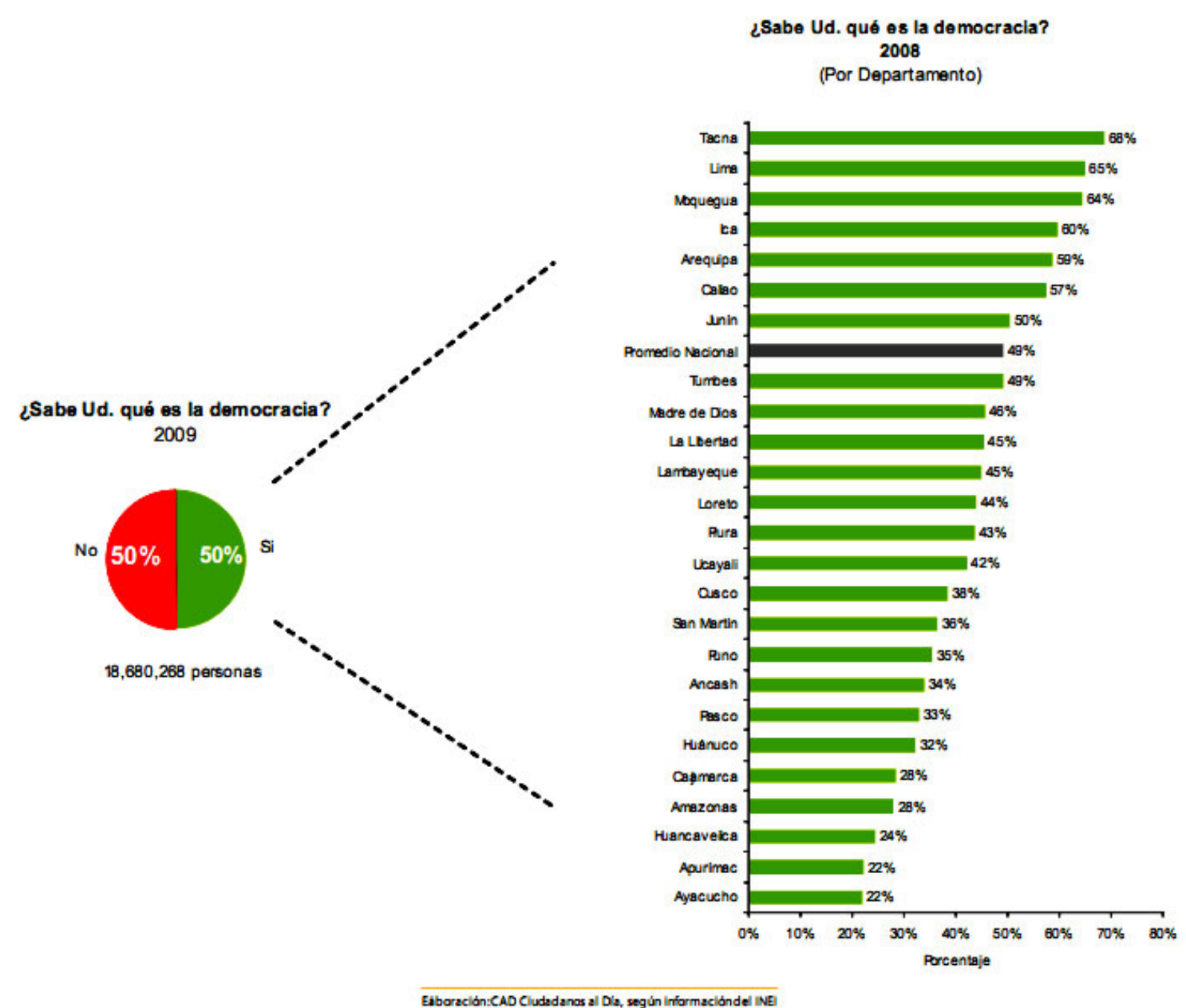

Fuente: Dr. Fontenoy entiendo que es CAD, Ciudadanos al día..., pero falta el año

Si partimos de las cifras del Latinobarómetro ya mencionadas que establecen que en el año 2009 en el Perú el 48\% de su población "no prefiere" la democracia, y se compara con las cifras del CAD, que nos señalan donde se indica que el 50\% de la población de este mismo Estado no sabe qué es la democracia, es plausible deducir que existe una relación entre el desconocimiento del concepto de democracia y su falta de preferencia hacia esta forma de gobierno.

Estas cifras le sugieren la idea al lector que en el Perú aún existen vastos sectores -especialmente entre los más pobres- que todavía no tienen muy claro lo que significa la democracia, la potencialidad social y las trascendentales consecuencias que, su gradual implementación, trae en la mejora de su calidad de vida.

Si bien en los países llamados "desarrollados" se han realizado importantes y destacables avances en el intento de crear una sociedad de seres humanos libres e iguales,es decir, una "sociedad democrática”, aún les queda 
también un largo trecho por andar. El ejemplo de los Estados Unidos, muestra las serias limitaciones que hasta hace pocos decenios supervivían en "el país de la democracia".

\section{CONCLUSIONES}

Este rápido repaso de algunos aspectos de la actual democracia, puede llevar a ciertas reflexiones, como las siguientes:

Que no se debe dedicar solamente a enfatizar la importancia de la democracia procedimental o electoral -que aunque la tiene-, es importante, más bien, hacer un mayor esfuerzo por tratar de difundir lo que es la democracia, su significado y lo que esto implica para la sociedad tanto en lo político como en lo económico y lo social): ya que, como se ha demostrado, todavía existe un enorme grupo de personas en el Perú y América Latina (y en casi todos los continentes) que no han llegado a conocer e informarse sobre la concepción de la democracia moderna y sus reales alcances sociales.

2. Que se está frente ante un enorme reto, tanto de los organismos e instituciones internacionales como de los Estados, medios de comunicación y sociedades civiles por difundir de manera masiva esta nueva visión democrática que debe de primar en las relaciones humanas de este nuevo siglo.

Si se analiza el surgimiento y el desarrollo de la democracia moderna desde una perspectiva histórica, de larga duración, además de hablar de transiciones o de las consolidaciones de ésta, creemos que habría de considerar el referimos a este se puede decir que el corto camino recorrido que la sociedad ha hecho, se le puede denominar como la construcción de la civilización democrática. 
